\title{
AUDIT SISTEM INFORMASI MENGGUNAKAN FRAMEWORK COBIT 4.1 PADA E-LEARNING UNISNU JEPARA
}

\author{
Noor Azizah \\ Universitas Islam Nahdlatul Ulama Jepara \\ Email: azizah@unisnu.ac.id
}

\begin{abstract}
ABSTRAK
Perkembangan teknologi saat ini tak bisa dibendung lagi. Kemajuan disetiap bidang tak lepas dari teknologi sebagai penunjangnya, terutama teknologi informasi. Akan tetapi hal tersebut harus dimbangi dengan adanya sebuah evaluasi atau audit terhadap sistem informasi sehingga ancaman atau kerugian dapat dihindari ataupun dicegah. Penelitian ini bertujuan mengetahui sejauh mana kinerja sistem informasi pembelajaran yaitu e-learning sebagai layanan publik yang telah diterapkan pada UNISNU Jepara dan memberikan rekomendasi tata kelola perbaikan setelah mengetahui kesenjangan antara tatakelola saat ini dengan tatakelola yang diharapkan sesuai dengan framework yang digunakan. Framework yang digunakan dalam penelitian ini adalah COBIT versi 4.1 khusus pada domain Deliver and Support (DS). Teknik pengumpulan datanya dilakukan dengan wawancara dan kuisioner dengan narasumber yang telah ditentukan sesuai dengan domain dan Control Objective yang digunakan. Metode analisis data dilakukan beberapa tahap, yaitu penentuan domain, penentuan proses kontrol, penentuan indikator dan pemetaan tingkatkematangan. Hasil dari penelitian ini adalah untuk mengetahui tingkat kematangan (maturity level) pada implementasi e-learning UNISNU Jepara khusus pada Domain DS, yaitu berada pada level 4 yang berarti sudah terukur dan terintegrasi antar proses yang berlangsung. Dan analisa GAP antara kondisi yang diharapkan dengan kondisi saat ini rata-rata sebesar 0,6.
\end{abstract}

Kata kunci: audit sistem informasi, e-learning, COBIT 4.1.

\section{ABSTRACT}

The development of today's technology can not be dammed again. But it must balanced with an evaluation or audit of information systems so that the threat or losses can be avoided or prevented. This study aims to determine the extent to which performance of the information system elearning UNISNU Jepara and provide governance improvement recommendations after finding out the gap between the current governance with governance expected according to the framework used. Framework used in this study is COBIT 4.1 version specifically on the domain Deliver and Support (DS). The technique of data collection is done by interviews and questionnaires with sources that have been determined in accordance with the domain and Control Objective used. Methods of data analysis was done in several stages, namely the domain determination, determination of process control, determination of indicators and maturity level mapping. Results of this study was to determine the level of maturity (maturity level) on the implementation of e-learning UNISNU special Jepara on Domain DS is at level 4 which means it's scalable and integrated process that takes place. And GAP analysis between the conditions expected with the current state average of 0.6 .

Keywords: information system audit, e-learning, COBIT 4.1.

\section{PENDAHULUAN}

Peran teknologi informasi maupun sistem informasi bagi dunia pendidikan sangatlah penting terutama di perguruan tinggi, hal ini menyebabkan peran teknologi informasi agar selaras dengan investasi yang telah dikeluarkan, sehingga dibutuhkan perencanaan yang matang serta implementasi yang optimal [1].

Universitas Islam Nahdlatul Ulama Jepara telah mengaplikasikan sistem pembelajaran berbasis $e$ learning sejak tahun 2015. e-learning merupakan aplikasi pembelajaran berbasis web yang tersedia untuk Dosen dan Mahasiswa yang memilki akun pada SIAkad, dalam e-learning dosen dapat memberikan tugas kepada Mahasiswa di kelasnya dan Mahasiswa dapat melihat seluruh tugas yang diberikan. Dosen juga dapat melakukan penilaianterhadap tugas yang dikerjakan oleh mahasiswa melalui e-learning. e-learning dirancang untuk membantu Dosen membuat dan mengumpulkan tugas tanpa kertas. Mahasiswa dapat melacak setiap tugas yang hampir mendekati batas waktu pengumpulan 
di laman Tugas. Dosen dapat melihat dengan cepatsiapa saja yang belum menyelesaikan tugas, serta memberikan masukan dan nilai langsung di e-learning.

Pemanfaatan teknologi informasi di perguruan tinggi juga harus didukung oleh IT Governance yang merupakan faktor penting dalam pemanfaatan teknologi informasi. Salah satu cara yang dapat diterapkan untuk mewujudkan IT Governance yang baik adalah dengan melakukan audit sistem informasi. Audit sistem informasi merupakan proses pengujian terhadap infrastruktur teknologi informasi untuk mengetahui apakah sistem yang sedang digunakan dan berjalan dapat menjamin keamanan aset yang dimiliki, integritas data, dan efektifitas operasi dalam mencapai tujuan yang telah ditetapkan[2].

ITGI (IT Governance Institute) menyatakan bahwa IT Governance mengintegrasikan dan menginstitusikan praktek yang baik untuk memastikan bahwa TI mendukung tujuan usaha. IT Governance memungkinkan perusahaan untuk mengambil keuntungan penuh dari informasinya, sehingga memaksimalkan keuntungan, memanfaatkan peluang dan mendapatkan keuntungan kompetitif [3].

\section{LANDASAN TEORI}

Audit sistem informasi merupakan proses pengumpulan dan pengevaluasian bukti untuk menentukan apakah sistem informasi ela menetapkan dan menerapkan sistem pengendalian intern yang memadai, semua aset dilindungi dengan baik dan tidak disalahgunakan serta terjaminnya integritas data, keandalan serta efektifitas dan efisiensi penyelenggaraan sistem informasi berbasis komputer [4]. Adapun tools yang dapat kita gunakan untuk audit sistem informasi adalah menggunakan kerangka kerja COBIT. Konsep kerangka kerja COBIT dapat dilihat dari tiga sudut pandang, yaitu (1) kriteria informasi (information criteria), (2) sumberdaya TI (IT resources), dan (3) proses TI (IT processes) [5]. Ketiga sudut pandang tersebut dapat digambarkan dalam kubus COBIT Gambar 1. :

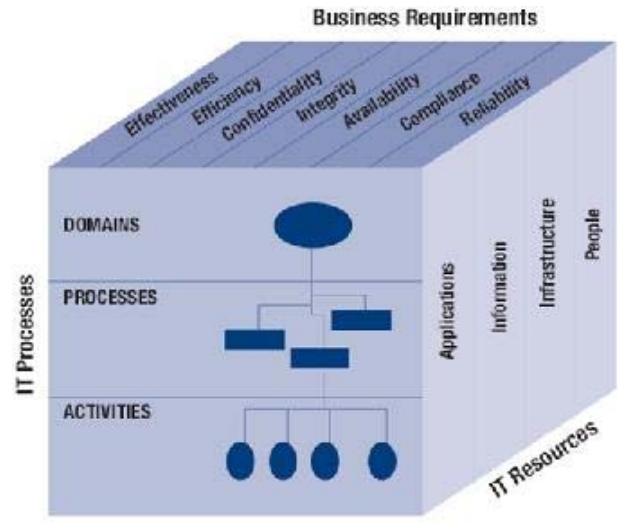

Gambar 1. Kerangka Kerja COBIT

Dalam kerangka kerja sebelumnya, domain diidentifikasikan dengan memakai susunan manajemen yang akan digunakan dalam kegiatan harian organisasi. Kemudian empat domain yang lebih luas diidentifikasikan menjadi 4 domain utama, yaitu :

1) Planning and Organization (PO)

Domain ini mencakup strategi dan taktik, dan perhatian atas identifikasi bagaimana TI secara maksimal dapat berkontribusi dalam pencapaian tujuan bisnis. Selain itu, realisasi dari visi strategis perlu direncanakan, dikomunikasikan, dan dikelola untuk berbagai perspektif yang berbeda. Terakhir, sebuah pengorganisasian yang baik serta infrastruktur teknologi harus di tempatkan di tempat yang semestinya

2) Acquisition and Implementation (AI)

Untuk merealisasikan strategi TI, solusi TI perlu diidentifikasi, dikembangkan atau diperoleh, serta diimplementasikan, dan terintegrasi ke dalam proses bisnis. Selain itu, perubahan serta pemeliharaan sistem yang ada harus di cakup dalam domain ini untuk memastikan bahwa siklus hidup akan terus berlangsung untuk sistem ini.

3) Delivery and Support (DS) 
Domain ini memberikan fokus utama pada aspek penyampaian/pengiriman dari TI. Domain ini mencakup area-area seperti pengoperasian aplikasi-aplikasi dalam sistem TI dan hasilnya, dan juga, proses dukungan yang memungkinkan pengoperasian sistem TI tersebut dengan efektif dan efisien. Proses dukungan ini termasuk isu/masalah keamanan dan juga pelatihan.

4) Monitoring and Evaluation (ME)

Semua proses IT perlu dinilai secara teratur sepanjang waktu untuk menjaga kualitas dan pemenuhan atas syarat pengendalian. Domain ini menunjuk pada perlunya pengawasan manajemen atas proses pengendalian dalam organisasi serta penilaian independen yang dilakukan baik auditor internal maupun eksternal atau diperoleh dari sumber-sumber alternatif lainnya.

Pengukuran tingkat kematangan diatur pada COBIT untuk tingkat manajemen dan memungkinkan para manajer mengeahui bagaimana pengellaan dan proses-proses IT di organisasi tersebut sehingga bisa diketahui pada tingkatan mana pengelolaannya. Model kematangan (maturity model) pada COBIT merupakan alat yang digunakan untuk mengukur seberapa baik proses pengelolaan TI yang berhubungan dengan kontrol internal IT yang juga berkaitan dengan tujuan bisnis organisasi [6]. Tingkat kemampuan pengelolaan teknologi informasi pada skala maturity dibagi menjadi 6 level, yaitu [5]:

1) Level o (non- existent)

Perusahaan tidak mengetahui sama sekali proses teknologi informasi di perusahaannya

2) Level 1 (initial level)

Pada level ini, organisasi pada umumnya tidak menyediakan lingkungan yang stabil untuk mengembangkan suatu produk baru. Pengembangan sistem sangat tergantung pada satu individu sebagai keahlian perorangan dan belum sepenuhnya diakui sebagai kebutuhan perusahaan.

3) Level 2 (repeatable level)

Pada level ini, kebijakan untuk mengatur pengembangan suatu proyek dan prosedur dalam mengimplementasikan kebijakan tersebut telah ditetapkan.

4) Level 3 (Defined level)

Pada level ini, proses standar dalam pengembangan suatu produk baru didokumentasikan, proses ini didasari pada proses pengembangan produk yang telah diintegrasikan.

5) Level 4 (managed level)

Pada level ini, organisasi membuat suatu matrik untuk suatu produk, proses dan pengukuran hasil. Proyek mempunyai kontrol terhadap produk dan proses untuk mengurangi variasi kinerja proses sehingga terdapat batasan yang dapat diterima.

6) Level 5 (optimized level)

Pada level ini, seluruh organisasi difokuskan pada proses peningkatan secara terus-menerus. Teknologi informasi sudah digunakan terintegrasi untuk otomatisasi proses kerja dalam perusahaan, meningkatkan kualitas, efektifitas, serta kemampuan beradaptasi perusahaan.

\section{METODE PENELITIAN}

\subsection{Metode Pengumpulan data}

Adapun langkah-langkah pengumpulan data adalah sebagai berikut :

1) Observasi

Merupakan metode pengumpulan data yang dilakukan dengan cara mengamati secara langsung kegiatan yang dilakukan di tempat penelitian untuk mendapatkan gambaran yang relevan dengan masalah dan tujuan penelitian. Pengumpulan data dilakukan di Universitas Islam Nahdlatul Ulam Jepara, seperti melihat bagaimana implementasi e-learning sehingga menemukan keadaan yang sebenarnya di lapangan.

2) Kuesioner

Kuesioner dilakukan dengan menyebarkan angket yang akan disebarkan kepada sejumlah responden. Adapun responden yang menjadi sasaran dalam Proses audit sistem informasi e-learning adalah Kepala UPT Pusat Data dan Pengembangan IT, Dosen, dan Mahasiswa

3) Wawancara

Merupakan sebuah proses memperoleh keterangan dengan cara tanya jawab sambil bertatap muka antara pewawancara dengan responden atau orang yang diwawancarai, dengan atau tanpa menggunakan pedoman wawancara. Wawancara dilakukan dengan tujuan mendapatkan informasi sebagai pendukung hasil kuesioner. Wawancara digunakan untuk menangkap informasi lebih lengkap mengenai masalah yang diteliti yang tidak terjaring melalui kuesioner. 


\subsection{Metode Analisis Data}

Setelah data-data terkumpul, tahap selanjutnya dalam penelitian ini adalah tahap pengolahan dan analisis data. Analisis data penelitian ini dibagi menjadi 2 bagian yaitu analisis tingkat kematangan (maturiry level) saat ini, analisis tingkat kematangan yang diharapkan dan analisis kesenjangan (gap analysis).

1) Analisis tingkat kematangan saat ini (as is)

Berdasarkan data hasil kuisioner dilakukan analisis untuk menilai tingkat kematangan saat ini (as-is) untuk domain DS. Pada analisis tingkat kematangan saat ini (as-is), dilakukan penilaian terhadap masing-masing aktivitas. Sedangkan untuk hasil jawaban kuesioner tingkat kematangan, akan tersedia 6 pilihan jawaban dengan nilai $0-5$. Tingkat kematangan atribut di peroleh dari perhitungan total pilihan jawaban kuesioner dikalikan dengan bobot dan dibagi dengan jumlah responden seperti pada rumus persamaan (1) :

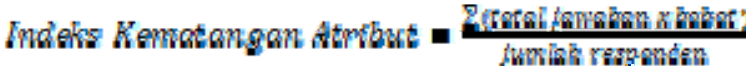

2) Analisis tingkat kematangan yang diharapkan (to be)

Penilaian tingkat kematangan yang diharapkan (to-be) bertujuan untuk memberikan acuan atau standar untuk pengembangan tata kelola TI di UNISNU. Tingkat kematangan yang akan menjadi acuan ke depan dalam proses layanan jasa dan pendukung dalam implementasi e-learningpada UNISNU Jepara dapat ditentukan dengan melihat faktor sebagai berikut :

a) Visi, misi dan tujuan UNISNU Jepara.

b) Hasil kuesioner

c) Wawancara dengan pihak pengelola dan pengguna

3) Analisis kesenjangan (gap)

Setelah diketahui tingkat kematangan saat ini (as-is) dan tingkat kematangan harapan (to-be) maka tahap selanjutnya adalah analisis kesenjangan. Analisis kesenjangan dilakukan untuk mengidentifikasi kegiatan atau perbaikan yang perlu dilakukan oleh pihak UNISNU Jepara agar tingkat kematangan bisa mencapai tingkat yang diharapkan. Tingkat kesenjangan diperoleh sesuai persamaan (2) yaitu tingkat kematangan yang diharapkan dikurangi dengan tingkat kematangan saat ini :

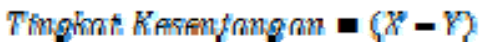

$X=$ tingkat kematangan yang diharapkan (to be)

$Y=$ tingkat kematangan saat ini (as is)

\section{HASIL DAN PEMBAHASAN}

\subsection{Tata Kelola IT Pada E-learning UNISNU}

Pengelolaan IT di UNISNU Jepara ini berada pada UPT Pusat Data dan IT. UPT Pusat Data dan IT mempunyai wewenang untuk menyediakan hal-hal yang berkaitan dalam pelayanan sistem informasi untuk mendukung kegiatan di lingkungan UNISNU termasuk di dalamnya e-learning. Keberadaan $e$ learning dalam proses kegiatan mengajar sangat membantu sekali karena disitu kita dapat berinteraksi aktif antara mahasiswa dan dosen. Akan tetapi keberadaan e-learning ini patut di audit agar keberlanjutan prosesnya bisa berjalan secara efektif.

\subsection{Analisis Maturity Level}

Kondisi kemampuan tata kelola TI saat ini dari e-learning UNISNU dapat diidentifikasi melalui analisis tingkat kematangan yang mengacu pada tingkat kematangan COBIT khususnya domain deliver and support. Analisis tingkat kematangan dapat diperoleh dari penyebaran kuesioner. Adapun jumlah responden pada penelitian ini sejumlah 37 orang. Rekapitulasi hasil kuesioner terlihat pada Tabel 1. : 
Tabel 1. Rekapitulasi hasil kuesioner

\begin{tabular}{ccc}
\hline Domain & Proses & Total \\
\hline DS 3 & Mengelola kinerja dan kemampuan & 149 \\
DS 5 & Memastikan keamanan sistem & 116 \\
DS 7 & Memberikan pelatihan kepada para pengguna & 115 \\
DS 9 & Pengelolaan konfigurasi & 132 \\
DS 10 & Pengelolaan permasalahan & 122 \\
DS 11 & Pengelolaan data & 138 \\
DS 13 & Pengelolaan operasi-operasi & 146 \\
\hline
\end{tabular}

Secara umum, setelah dilakukan proses penghitungan pada tujuh proses dalam domain deliver and support, 4 proses mempunyai tingkat kematangan 4 (managed and measurable) dan 3 proses lainnya mempunyai tingkat kematangan 3 (defined process) seperti terdeskripsikan pada tabel 2 .

Tabel 2. Current maturity domain DS

\begin{tabular}{ccc}
\hline Domain & Indeks & Level \\
\hline DS 3 & 4.03 & 4 \\
DS 5 & 3.14 & 3 \\
DS 7 & 3.11 & 3 \\
DS 9 & 3.57 & 4 \\
DS 10 & 3.30 & 3 \\
DS 11 & 3.73 & 4 \\
DS 13 & 3.95 & 4 \\
\hline Rata-rata & & 3.54 \\
\hline
\end{tabular}

Dari tabel 2 terlihat bahwa secara umum, tingkat kematangan implementasi e-learning UNISNU khususnya pada domain deliver and support berada pada tingkat 4 (managed and measurable). Hal ini berarti bahwa kegiatan atau standar yang berkaitan dengan implementasi e- learning UNISNU telah diterapkan secara formal dan saling terintegrasi. Serta terdapat pula indikator sebagai pengukur kemajuan kinerja secara kuantitatif bagi pihak managemen. Lalu terdapat perbaikan yang konstan terhadap proses yang ada. Namun penggunan otomasi masih terbatas pada proses tertentu.

\subsection{Analisis GAP Maturity Level}

Target atau harapan kematangan proses tata kelola teknologi informasi merupakan kondisi ideal tingkat kematangan proses yang diharapkan, yang akan menjadi acuan dalam model tata kelola TI e-learning UNISNU yang akan dikembangkan. Target atau harapan kematangan proses tata kelola teknologi informasi dapat ditentukan dengan melihat lingkungan internal bisnis UNISNU seperti visi dan misi, tujuan universitas maka dapat ditetapkan bahwa untuk dapat mendukung pencapaian tujuan UNISNU maka tingkat kematangan yang dilakukan harus ada pada tingkat 5 (optimised) pada proses DS 3 dan tingkat 4 pada proses DS 5, DS 7, DS 9, DS 10, DS 11, dan DS 13. Adapun nilai GAP maturity level dapat dilihat pada tabel 3.

Tabel 3. GAP Maturity Level

\begin{tabular}{cccc}
\hline Proses & \multicolumn{3}{c}{ Tingkat Kematangan } \\
\cline { 2 - 4 } & Saat ini & Harapan & Gap \\
\hline DS 3 & 4.03 & 5 & 0.97 \\
DS 5 & 3.14 & 4 & 0.86 \\
DS 7 & 3.11 & 4 & 0.89 \\
DS 9 & 3.57 & 4 & 0.43 \\
DS 10 & 3.30 & 4 & 0.70 \\
DS 11 & 3.73 & 4 & 0.27 \\
DS 13 & 3.95 & 4 & 0.05 \\
\hline
\end{tabular}


Berdasarkan paparan diatas, maka dibuatlah rekomendasi berupa pengelolaan IT yang lebih intensif terhadap penggunaan e-learning. Selain itu, perlu diadakan sosialisasi maupun pelatihan terhadap penggunaan $e$-learning agar penggunaan nya bisa lebih maksimal. Pihak managemen UPT Pusat Data dan IT juga harus berkomitmen terhadap tingkat keamanan dan pengelolaan prosesproses yang sudah cukup baik ini agar terus ditingkatkan. Peningkatan tingkat kematangan juga harus dilakukan sesuai dengan standar COBIT agar UNISNU dapat menerapkan pengelolaan IT yang baik (Good Governance).

\section{KESIMPULAN}

Berdasarkan penelitian yang telah dilakukan, maka dapat diambil kesimpulan sebagai berikut :

1) Proses audit sistem informasi terhadap e-learning yang berjalan di UNISNU Jepara dilakukan menggunakan standar framework COBIT 4.1 khusus pada domain deliver and support (DS) khusus pada proses DS 3, DS 5, DS 7, DS 9, DS 10, DS 11, DS 13.

2) Hasil tingkat kematangan (maturity level) pada implementasi e-learning UNISNU Jepara khusus pada domain DS berada pada level 4 yang berarti sudah terukur dan terintegrasi antar proses yang berlangsung Analisa GAP antara kondisi yang diharapkan dengan kondisi saat ini rata-rata adalah 0,6 dengan rekomendasi perbaikannya ditekankan pada peningkatan keamanan sistem dan memberikan pelatihan dan sosialisasi yang lebih intens agar keberalangsungan e-learning dapat maksimal.

\section{DAFTAR PUSTAKA}

[1] Wardani, S and Puspitasari, M. 2014. "Audit Tata Kelola Teknologi Informasi Mengunakan Framework Cobit Dengan Model Maturity Level (Studi Kasus Fakultas ABC)”. Jurnal. Teknologi. volume 07. 38-46.

[2] Gustiarni, I., and Putra, S. A., Murahartawaty "Pengembangan Aplikasi e-university: Sistem Infromasi Pengelolaan Audit Teknologi Informasi Berbasis Risiko Menggunakan Framework COBIT Versi 4.1".

[3] Ron, W. (1999). EDP Auditing-Conceptual Foundatins And Practice. USA. Mc Graw- Hill, Inc,

[4] Wahono, B, B. 2015. "Peningkatan Layanan Sistem Informasi Kesehatan (Studi Kasus Dinas Kesehatan Kabupaten Jepara)". SIMETRIS, volume 6, 1, 101-110.

[5] I. G. Institute. (2007). COBIT Ver. 4.1 : Framework, Control Objectives, Management Guidelines, Maturity Models. Rolling Meadow.

[6] Supradono, B. 2011. "Tingkat Kematangan Tata Kelola Teknologi Informasi (IT Governance) Pada Layanan Dan Dukungan Teknologi Informasi (Kasus: Perguruan Tinggi Swasta Di Kota Semarang)”vol. 11. 